\title{
Impact of mission requirements on the design of low observable UCAV configurations
}

\author{
E. Sepulveda, H. Smith \\ SATM, Cranfield University, Cranfield, UK.
}

Purpose - The purpose of this paper is to characterise the effects of mission and performance parameters on the design space of low observable subsonic unmanned combat aerial vehicles operating in typical Hi-Lo-Hi ground strike missions.

Design/methodology/approach - Conceptual design methodologies appropriate to low observable, tailless UCAVs have been integrated into a multidisciplinary aircraft design environment, GENUS, developed at Cranfield University's Aircraft Design Group. A basic Hi-Lo-Hi mission is designed and a baseline configuration is established through the GENUS framework. Subsequently, an evolutionary optimiser and a robust gradient-based optimiser are employed to obtain convergent design solutions for various leading edge sweep angles, mission ranges, cruise Mach numbers, and other operational constraints.

Findings - The results indicate that performance constraints, specifically in the form of specific excess power, have a large influence on the overall sizing of subsonic tailless UCAVs. This requirement drives the engine sizing which represents a considerable proportion of the empty and gross mass of the vehicle. Cruise Mach number studies show that no significant advantages exist for operating at low speeds while maintaining performance requirements consistent with combat missions. There is a drastic increase in the vehicle's mass and thrust requirements for flight speeds above Mach 0.8 , with low sweep configurations showing a more pronounced effect. Increases in range are not overly dependent on the leading edge sweep angle. Top-level radar cross section results also favour configurations with higher leading edge sweep angles, especially from the nose-on aspect. Finally, research and development costs are shown to be directly linked to engine size.

Originality/value - This research shows the use of an integrated aircraft design environment that incorporates aerodynamics, performance, packaging, and low observability aspects into the optimisation loop. Through this methodology, this study supports the efforts towards characterising and establishing alternate visions of the future of aerial warfare through the use of low cost, survivable unmanned platforms in network-centric cooperative tasks.

Keywords UCAV; MDAO; conceptual design; stealth; fighter; drone; loyal wingman

Paper type Research paper

\section{Introduction}

Unmanned aerial vehicles (UAV) have significantly transformed aerial warfare. In the past, UAVs have proven their value mainly in surveillance, communication relay, and decoy roles, even achieving the first surrender to a surveillance unmanned aircraft during the Persian Gulf War (Dixon, 2000). In 2001, Predator UAVs armed with laser-guided missiles fired against active targets, marking a new stage of UAV employment in combat. This class of vehicles, however, cannot operate in contested environments due to their low speed and limited manoeuvrability, relying mainly on sustained surveillance at high altitudes for their continued operations.

Indeed, a thorough analysis of the vulnerabilities affecting UAVs and remotely piloted aircraft (RPA) employed in military roles has determined that present configurations are not fit to serve in contested environments due to their severe 
vulnerabilities to manned fighters, surface-to-air defence systems, portable air defence weaponry, electronic jamming, and loss of communication and control beyond the line of sight (Haider, 2014).

Therefore, Unmanned Combat Aerial Vehicles (UCAV) have emerged as the new generation of unmanned platforms capable of operating in highly contested environments through a combination of high speed, improved manoeuvrability, advanced sensors and very low observability. This new class of combat vehicles will most likely perform pre-emptive and reactive suppression and destruction of enemy air defences (S/DEAD), strike of high value targets, electronic warfare, and eventually, air-to-air combat (Wise, 2003).

Furthermore, the transition towards fifth generation forces will mandate the adoption of new and advanced technologies such as all-around stealth, on-board and off-board sensor data fusion, and an increased ability to integrate and work cooperatively with a number of aerial, maritime, and ground based systems (Adamson and Snyder, 2017). This transition also requires the development of new platforms with multirole capabilities supported by innovative technolgies and high component commonality between variants. An example of this is the stealthy F-35 Joint Strike Fighter, which uses the innovative dual-cycle propulsion system (Bevilaqua, 2009), and advanced information fusion which results in improved situational awareness for pilots and operators, improved accuracy, and an effective tactical network with legacy aircraft (Frey Jr et al., 2018).

As a direct response to this demand, countries like India (Jane's 360, 2019), Australia (UK Defence Journal, 2019), and the US (Wright-Patterson AFB, 2019), have announced the development and testing of subsonic UAVs intended to act in conjunction with manned aircraft, as low cost options that offer 'game changing combat capabilities'. These 'loyal wingmen' will operate within the high subsonic flight regime, with payloads starting from $250 \mathrm{~kg}$. The use of advanced human-centered mission planning and autonomy software currently being developed will most likely form an integral part in their future deployment (BAE Systems, 2019).

These estimated performance levels match well with the envisioned future of aerial warfare presented by Stillion, where UCAVs of moderate performance, payload, and low observability, advanced sensors, data fusion, and higher levels of autonomy could operate in highly contested airspace against high-performance enemy fighters, and other advanced defence systems at a fraction of the cost and risk to human operators (Stillion, 2015).

Throughout this research, the authors aim to explore the main performance trade-offs for subsonic, low observable, tailless UCAV configurations that could potentially act as loyal wingmen and force multipliers to manned fighters. Low observability design aspects are incorporated through shaping and system choices, but a more in-depth look at stealth needs to be carried out before drawing any conclusions. A typical Hi-Lo-Hi mission is evaluated for configurations of varying sweep angles and constant wing area, and important mission parameters such as cruise Mach number, combat radius, and specific excess power (SEP) are varied in order to characterise the response space of such vehicles.

\section{The GENUS aircraft design environment}

Multidisciplinary design analysis and optimisation (MDAO) plays a key role in the conceptual design studies of novel aircraft configurations. Computerised aircraft design environments are currently being applied to the analysis and optimisation of whole configurations, aircraft systems, and subsystems reducing research and development costs, time, and risks.

Presently, there is a need to compare different classes of aircraft through equivalent methodologies in order to quantify the real differences and advantages, if any, that each configuration can offer. The GENUS aircraft design environment, which has been under development at Cranfield University's Aircraft Design Group since 2012, aims to address this need 
through a common central architecture, which consists of 9 interconnected essential modules distributed in several levels of abstraction and polymorphism necessary for designing and analysing several 'species' of aircraft.

GENUS relies on a central philosophy that combines the expertise of 'knowledgeable designers' with computerised, wellproven aircraft design methodologies (Smith et al., 2018). Furthermore, any number of 'special modules' can be added in order to evaluate non-typical aircraft design aspects such as stealth, noise prediction, sonic boom intensity, or aerodynamic heating. The top-level interaction between the GENUS modules is shown in Figure 1 in the form of an $\mathrm{N}^{2}$ diagram, and the main methodologies appropriate for subsonic UCAV configurations are explained in the sections below. GENUS has been applied to the conceptual design of hypersonic launchers and transports, conventional and blended wing body airliners, solar-powered UAVs, supersonic business jets (Sun and Smith, 2018), and subsonic tailless UCAVs (Sepulveda et al., 2018). Future implementations of the GENUS framework include hybrid electric passenger jets, as well as supersonic UCAVs.

\section{Mass Estimation}

Due to the novelty of UCAV configurations and to the lack of empirical data, a combined approach has been developed following recommendations by Gundlach (Gundlach, 2012), mainly relying on Class II mass prediction methods for manned fighters (Raymer, 1992; Roskam, 1985). Technology reduction factors are applied in order to account for novel materials and manufacturing practices, so that the mass estimation of structural components are reduced by a conservative factor between $10 \%$ and 15\% (Lewis, 1994), (Resetar et al., n.d., p. 29). Results in Table 1 show good agreement for maximum take-off mass (MTOM) and operating empty mass (OEM) in subsonic UCAV demonstrators and concepts (Smith, 1999, 2003, Wikipedia, n.d., n.d.). Mass values have been estimated for Taranis and Neuron by estimating the payload based on similar configurations, as well as by averaging the payload and empty weight ratios of various demonstrators and concepts available in the literature.

Table 1 Mass breakdown validation for subsonic UCAVs.

\begin{tabular}{|c|c|c|c|c|}
\hline \multirow{2}{*}{ Model } & \multicolumn{2}{|c|}{ MTOM } & \multicolumn{2}{|c|}{ OEM } \\
\hline & Quoted & GENUS & Quoted & GENUS \\
\hline$X-47 B$ & 20215 & 21021 & 6350 & 7903.5 \\
\hline$X-45 C$ & 16556 & 16994 & 8154 & 8361.7 \\
\hline Taranis & 8000 & 8749 & 4200 & 4948 \\
\hline Neuron & 7000 & 7740.3 & 4900 & 5740.3 \\
\hline U-3 Cranfield & 11780.6 & 11079.7 & 4841.9 & 5079 \\
\hline U-99 Cranfield & 4877 & 4630.5 & 3253 & 2510 \\
\hline
\end{tabular}

Figure $1 \quad \mathrm{~N}^{2}$ diagram for the GENUS framework. 


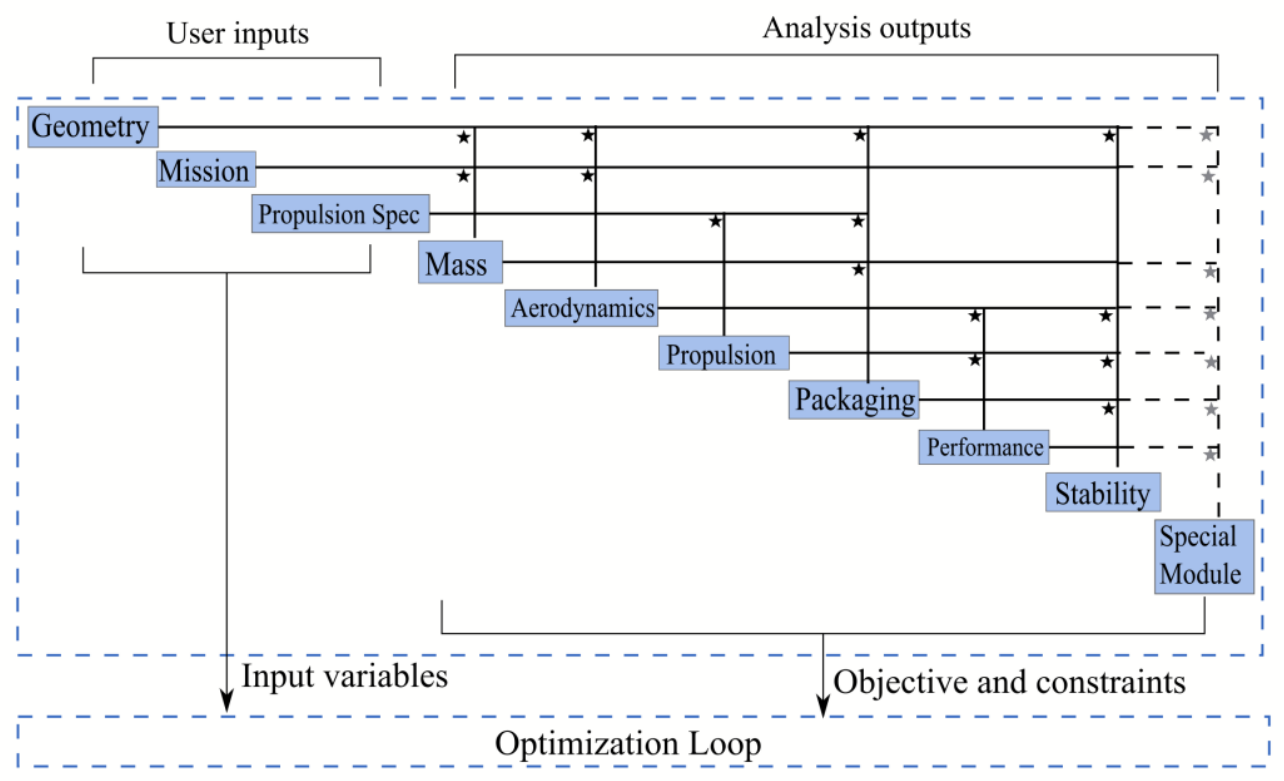

Aerodynamic Modelling

High fidelity studies concerning the aerodynamics of typical UCAV configurations have found complex flow topologies dominated by leading edge vortex interactions (Petterson, 2006; Tomac et al., 2010; Verhaagen, 2011). Computationally expensive CFD solvers are often employed in single design point studies; however this approach is not practical for large design space exploration studies at a conceptual design level. The GENUS framework employs the higher order subsonic and supersonic potential flow solver PANAIR (Sidwell et al., 1990) for the main aerodynamic analysis, augmented by semi-empirical drag modelling (Gur et al., 2010; Virginia Tech, n.d.), as shown in Eqns 1 to 6.

A geometry format that automatically converts discrete geometry elements into structured networks and their corresponding wakes has been developed. The FORTRAN-based PANAIR solver is linked to the GENUS framework via Java Native Interface (JNI) and a C++ wrapper file which transfers data to and from FORTRAN via 'Extern C' calls. Outputs are then collected and transferred to Java through the same $\mathrm{C}++$ wrapper file, as shown schematically in Figure 2. These files are then compiled into a dynamic-link library (DLL) object which can be statically loaded from the main GENUS framework. This approach results in faster execution time when compared to writing/reading procedures often found in other frameworks. Results in Figure 3 show good agreement against low speed wind tunnel data for Boeing's 1303 UCAV configuration, for which an equivalent platform has been modelled in GENUS (McParlin et al., 2006). The validity of the pitching moment coefficient has been limited to moderate angles of attack due to the lack of appropriate modelling of the complex vortex interactions normally found in typical UCAV configurations.

Figure 2 Java/C++/FORTRAN data transfer process for aerodynamics. 


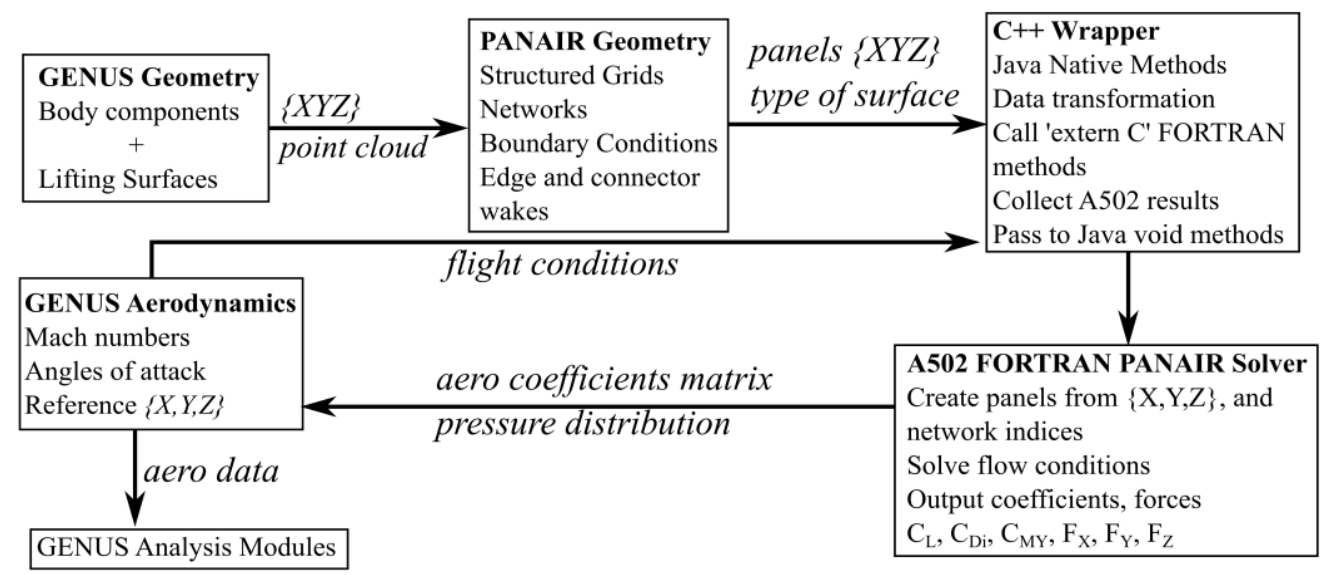

Figure 3 Low speed validation: PANAIR vs wind tunnel data for 1303 UCAV.

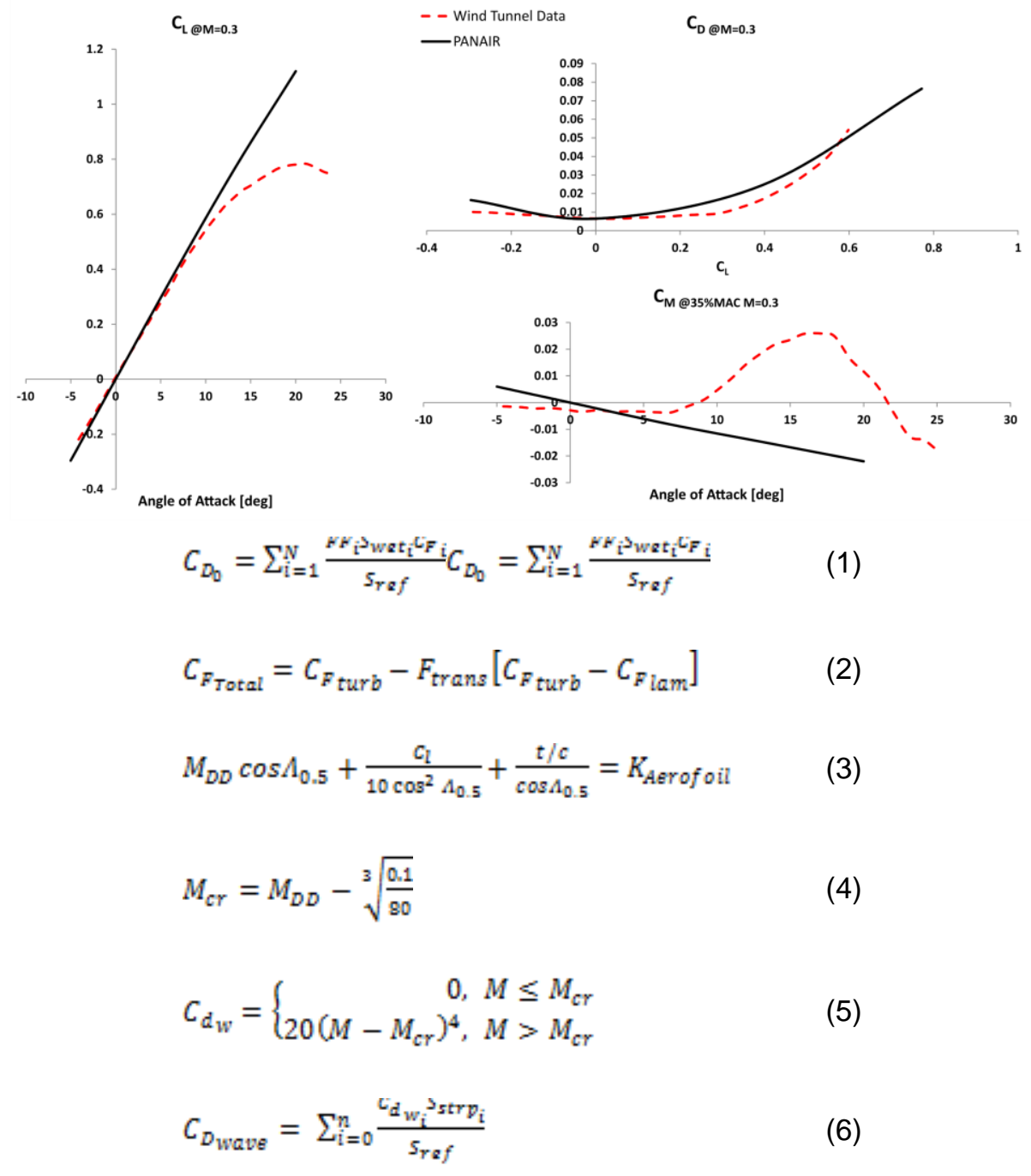

\section{Where:}

$\mathrm{FF}_{\mathrm{i}}$ is the component's form factor

$S_{\text {wet }}$ is the wetted area of each component $\left(\mathrm{m}^{2}\right)$

$S_{\text {ref }}$ is the reference area $\left(\mathrm{m}^{2}\right)$

$\mathrm{C}_{\mathrm{Fi}}$ is the component's skin friction coefficient

$F_{\text {trans }}$ is the percentage of laminar flow (user input) 
$\mathrm{K}_{\text {Aerofoil }}$ is the aerofoil factor for subsonic wave drag ( 0.87 for regular aerofoils, 0.95 for supercritical aerofoils)

$M_{D D}$ is the divergence Mach number, defined as the Mach number that produces a drag increment of 0.002

$M_{c r}$ is the critical Mach number

$\mathrm{C}_{\mathrm{dw}}$ is the contribution of individual wing strips to the total wave drag coefficient

$\mathrm{C}_{\text {Dwave }}$ is the total wave drag coefficient

Propulsion

Several levels of fidelity are available inside the GENUS propulsion module, from simple empirical regression models (Howe, 2000), to a physics-based analysis of turbofan, turbojet (dry and re-heat), and ramjet engines adapted from the open source EngineSim applet (Benson, 1995; NASA Glenn Research Center, 2015). The propulsion specification module allows the user to set the design characteristics of the powerplant, including design Mach number and altitude, maximum Mach number, overall diameter, bypass ratio, fan and compressor pressure ratio, as well as material choices in order to incorporate temperature limits and calculate weight through the idealised volumes shown in Eqn. 7 and Figure 4. Once the design has been set, the propulsion module uses the 'test mode' and evaluates the off-design performance of the propulsion system. This performance data can then be accessed by the rest of the analysis modules at any combination of Mach, altitude, throttle setting, and afterburner mode.

Results have been validated against a J79 turbojet in dry mode with good agreement as shown in Figure 5.

$$
W_{\text {Engine }}=\frac{\pi}{4} \sum_{i=0}^{n} P_{i} L_{i} d_{i}^{2}
$$

Figure 4 Powerplant weight estimation in EngineSim.

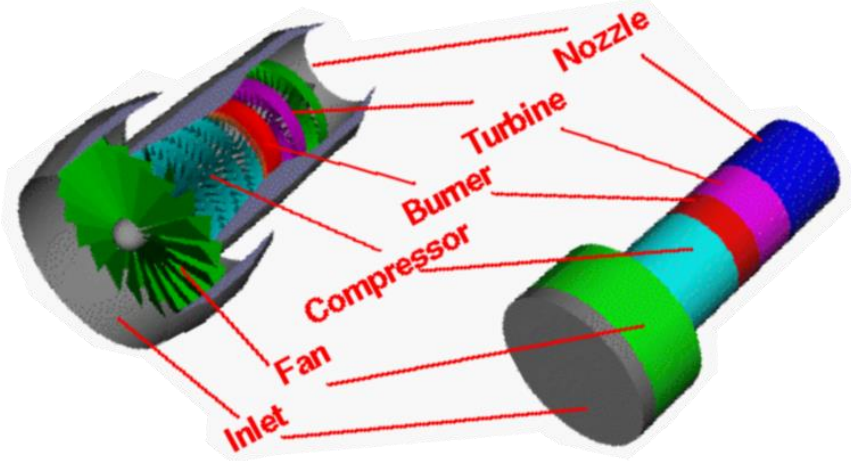


Figure 5 Validation of propulsion models inside GENUS.
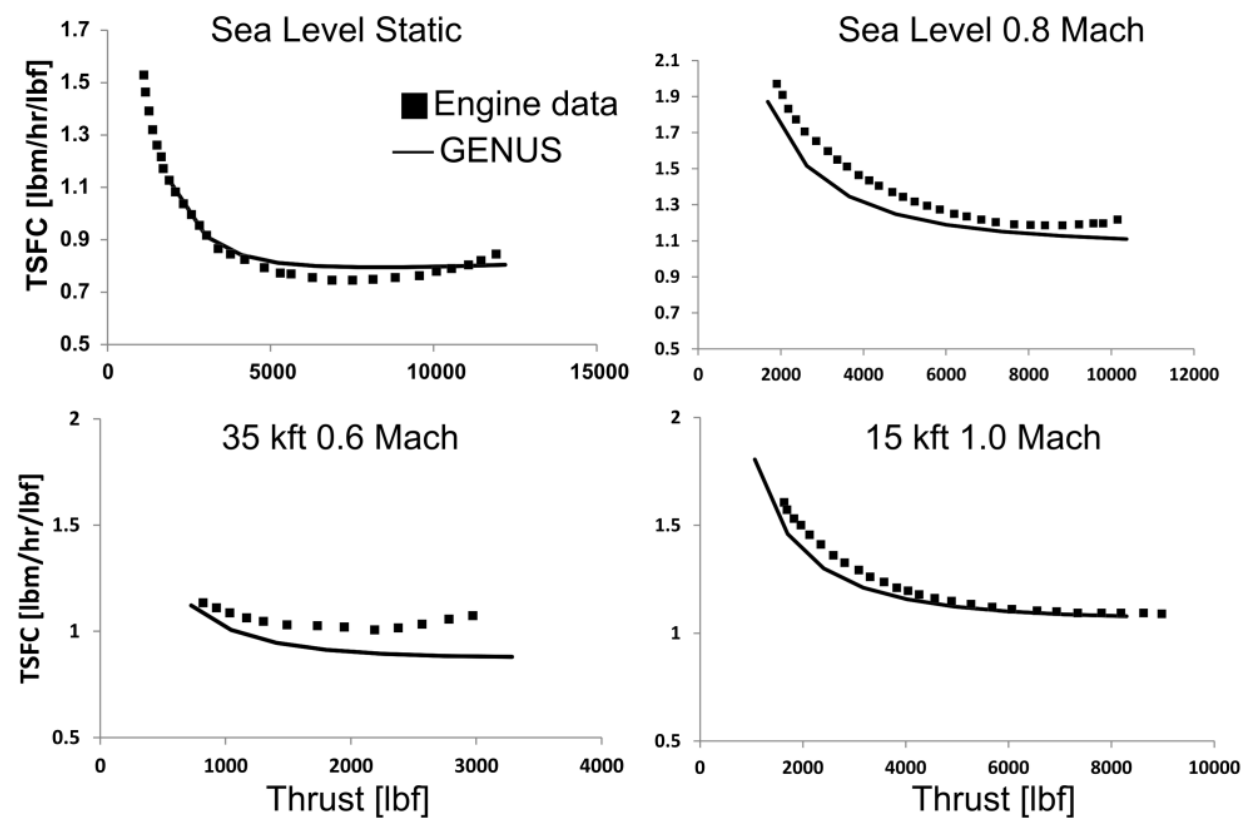

Packaging and centre of gravity

The packaging and centre of gravity (CG) module calculates the fuel volume available inside the wing structural box, as well as in other selected locations depending on the configuration's internal arrangement of powerplant and payload bays. Centre of gravity locations are calculated for all mass conditions throughout the mission profile. In the case of distributed fuel tanks, fuel scheduling can be modified in order to adjust the overall CG position and obtain better longitudinal stability. This module also has the flexibility to move items in the longitudinal and lateral directions in order to obtain acceptable CG limits, as well as to resolve clashes with other items. Landing gear loads, size, and positioning calculations are also carried out in this module.

\section{Mission and performance}

Different combat missions can be specified parametrically for any given number of mission segments or phases, which can be fully defined by specifying segment type, initial and final conditions, and minimum performance levels for the cases of point performance and manoeuvrability. Combat missions such as ground strike, multirole strike fighter, air superiority, and deep interdiction can be easily investigated through this functionality.

Normal runway take-off procedures have been adapted from Lynn's TAKEOFF.C code and results have been verified against the original source code (Lynn and Pete, 1994). Climb segments are modelled through the optimised energy height climb methods (ESDU, 1991); cruise segments can be modelled as constant altitude and speed, constant altitude and attitude, and constant speed and attitude (Gudmundsson, 2014, chap. 20). Instantaneous turn rates are evaluated through maximum wing loading, or maximum lift coefficient, while sustained turns are evaluated through drag/thrust requirements as shown in Eqn 8. Acceleration requirements are evaluated through average acceleration and available SEP as shown in Eqn 9 and Eqn. 10 (Cranfield College of Aeronautics, n.d.).

$$
\begin{aligned}
& D_{S T}=q C_{D_{0}} S_{r e f}+\frac{K(n W)^{2}}{q S_{r a f}} \\
& P_{S}=\frac{V}{g}\left(\frac{V_{f i n a l}-V_{\text {initian }}}{\Delta t}\right)
\end{aligned}
$$




$$
P_{s}=V\left[\frac{T}{W}-\frac{q C_{D}}{W / 5}-n^{2} \frac{K W}{q S}\right]
$$

Where:

$D_{S T}$ is the drag generated during a sustained turn $(N)$

$\mathrm{q}$ is the dynamic pressure $(\mathrm{Pa})$

$\mathrm{K}$ is the induced drag factor

$\mathrm{n}$ is the load factor

$\mathrm{W}$ is the weight of the aircraft $(\mathrm{N})$

Ps is the specific excess power $(\mathrm{m} / \mathrm{s})$

$\mathrm{V}$ is the instantaneous speed of the aircraft $(\mathrm{m} / \mathrm{s})$

$\mathrm{g}$ is the gravitational acceleration constant $\left(\mathrm{m} / \mathrm{s}^{2}\right)$

$\Delta \mathrm{t}$ is the acceleration time requirement (s)

Stability

Static margin and longitudinal trim calculations have been automated by the integration of Digital DATCOM into the GENUS framework through the legacy code linking process explained before and schematically shown in Figure 6 below. A geometry format has been developed in order to convert discrete geometry elements, control surface dimensions and types, and flight conditions into DATCOM appropriate inputs.

Figure 6 GENUS to DATCOM data sharing and processing.

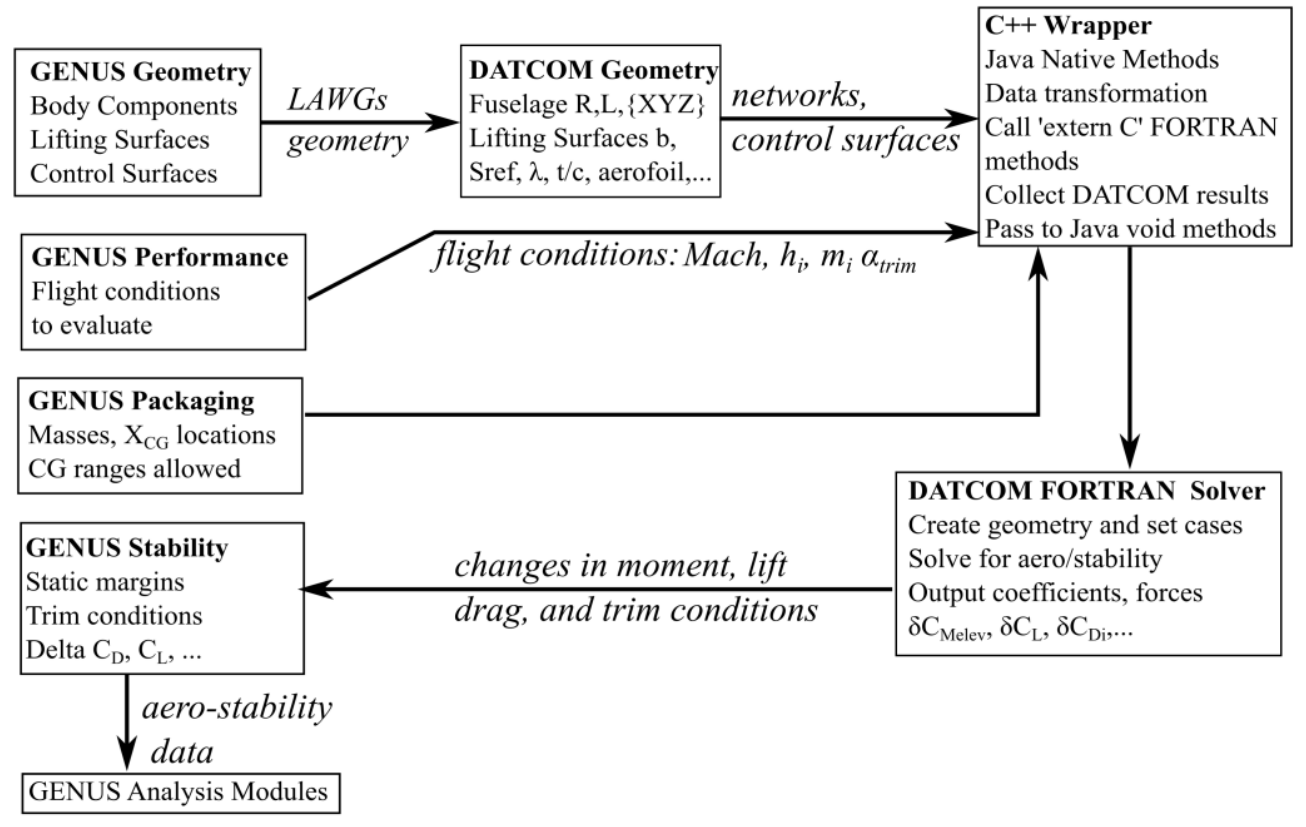

\section{Radar cross section}

Stealth, or low observability, requirements are some of the most demanding constraints applied to military aircraft today. A complete account of low observable design criteria includes visual signature, auditory signature, thermal signature, and electromagnetic signature. During the conceptual design phase, low observability techniques can be included through vehicle shaping, mission planning, material selection, and structures and systems layout criteria such as low observable inlets, internal weapon bays and low observable nozzles and exhausts (MacDiarmid, 2010). 
Stealth constraints currently implemented into the GENUS framework are limited to electromagnetic signature estimation through calculations of monostatic radar cross section (RCS) based on physical optics approximations adapted from the freely available POFACETS code (Chatzigeorgiadis, 2004; Garrido, 2000; MathWorks, 2012). The RCS signature is defined in relation to the incident and scattered fields in Eqn 11, and it is a measure of the cross sectional area of a reflecting sphere that would reflect the same amount of energy as the actual target (Rao and Mahulikar, 2002). For a comprehensive review of stealth technology and its impact on aircraft design, see (Jenn, 2005).

In order to evaluate the radar signature at any combination of azimuth $(\theta)$ and rotation $(\phi)$ angles, discrete geometrical components are transformed into a collection of triangular facets through the use of three-dimensional convex hulls and Delaunay triangulation routines (Lloyd, 2004). Each facet is identified by the coordinates of its vertices, the coordinates of its centre-point, and the direction of its normal vector in three-dimensional space, as well as an element identifier number. The total RCS signature at any combination of azimuth and rotation angle is the superposition of the contributions of all individual facets; in the case of a facet not being 'illuminated' by the incident wave, its contribution is zero at that particular orientation. Results have been validated against the original code with excellent agreement, as shown in Figure 7.

Figure 7 Monostatic RCS validation in GENUS.

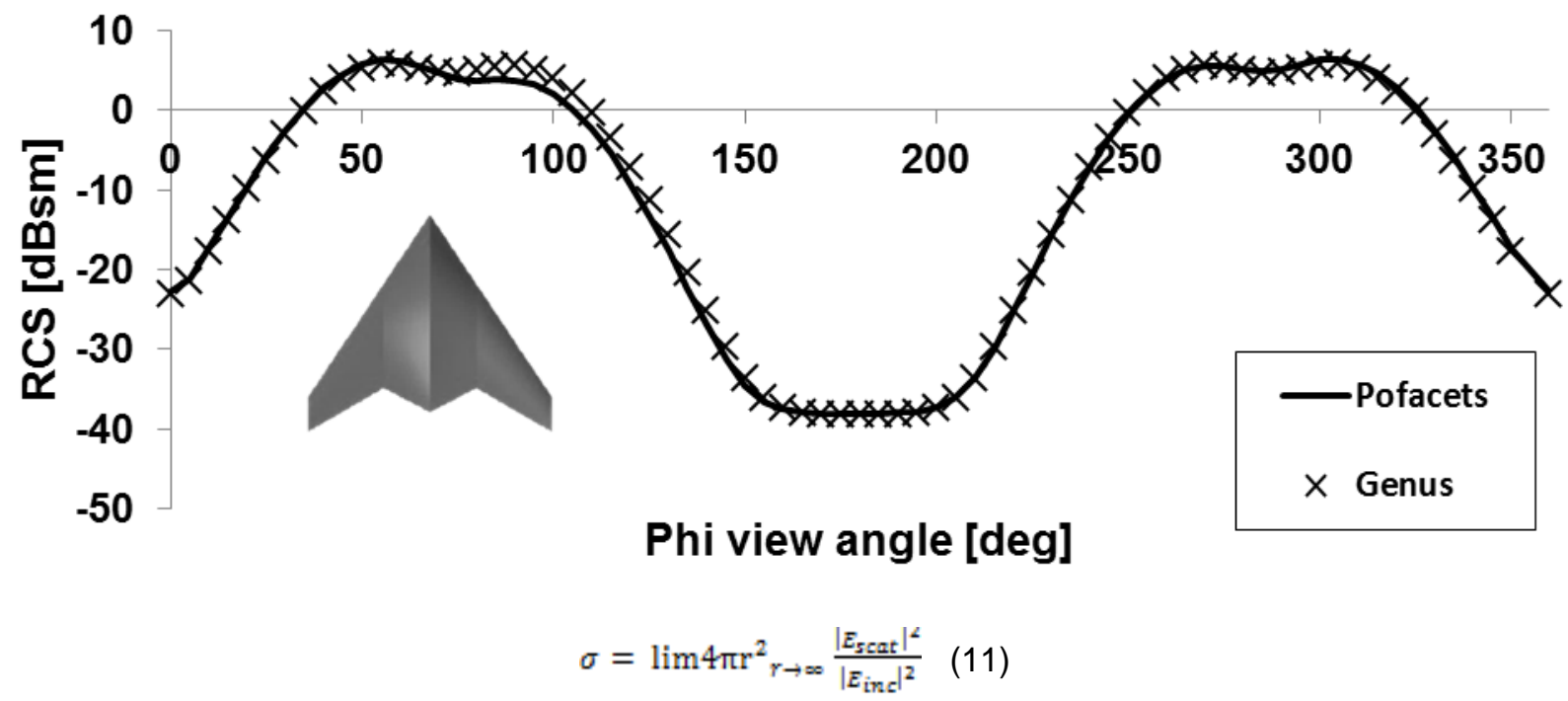

Where:

$\sigma$ is the radar cross section $\left(\mathrm{m}^{2}\right)$

$r$ is the range between the radar and the target $(\mathrm{m})$

$E_{\text {scat }}$ is the scattered electromagnetic field $(N / C)$

$E_{\text {inc }}$ is the incident electromagnetic field $(N / C)$

Optimisation

As described earlier, the central philosophy behind the GENUS aircraft design environment combines the expertise of aircraft designers with well-proven computerised aircraft conceptual design methodologies. When designing novel configurations, the role of the designer is to select, develop, and integrate the appropriate methodologies, and the role of the framework is to generate new knowledge based on the initial assumption, and taking into consideration the domain of applicability of each discipline. This positive knowledge feedback loop leads to ever more refined studies and analyses. Different levels of abstractions are dealt with through a design and optimisation process. As an example, different geometry formats employed during various design stages are shown in Figure 8 
The GENUS framework makes use of two optimisation algorithms in multivariate, single-objective optimisation. A custom made evolutionary algorithm can be used to explore larger portions of the design space avoiding falling into local minima, and the robust LSGRG2 algorithm (Smith and Lasdon, 1992) can be used to refine results within a specific region of the design space, resulting in an efficient hybrid approach.

Figure 8 Wireframe, aerodynamic panels, RCS (facet normal vectors), and packaged CATIA geometries
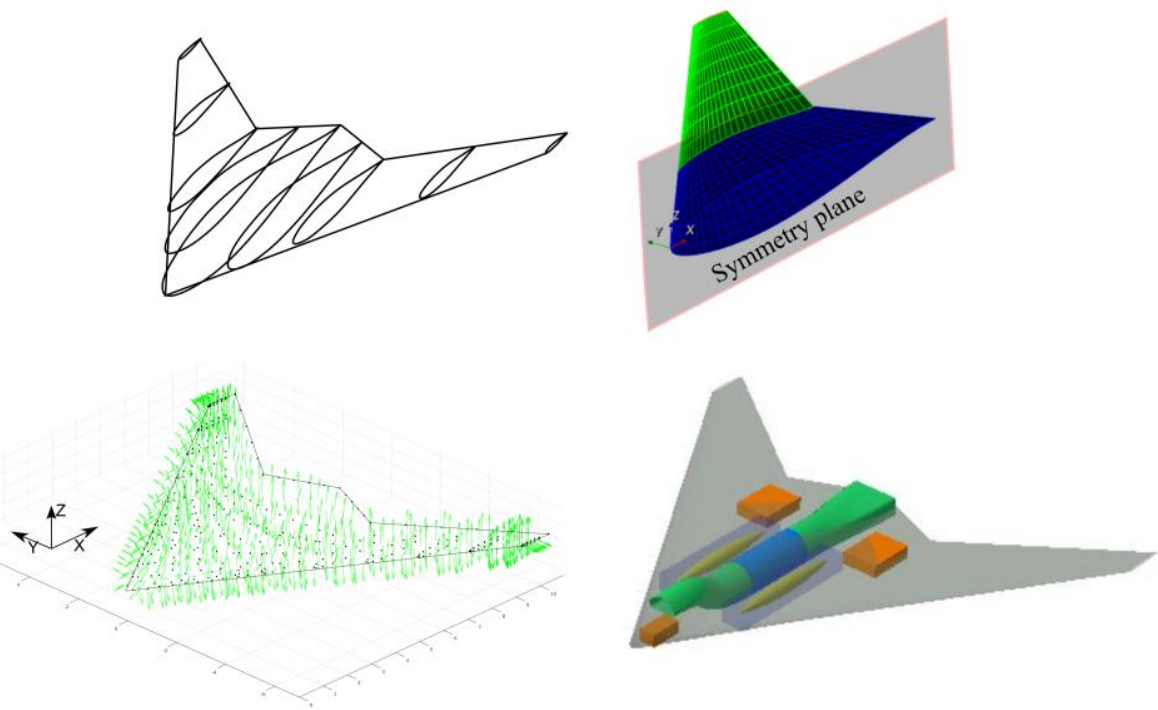

\section{Mission specification and performance trade-offs}

The basic Hi-Lo-Hi mission parameters are based on AIAA's unmanned strike fighter design competition specifications (AIAA, n.d.), and shown in Table 2, while the minimum performance requirements are given in Table 3.

Table 2 Basic Hi-Lo-Hi mission description.

\begin{tabular}{ll}
\hline Phase & Description \\
\hline $0-1$ & Warm up and take-off \\
$1-2$ & Minimum time to climb to $0.8 \mathrm{M} / 12200 \mathrm{~m}$ \\
$2-3$ & Cruise out segment $0.8 \mathrm{M} / 12200 \mathrm{~m}, 1400 \mathrm{~km}$ \\
$3-4$ & Descent to $0.8 \mathrm{M} / 250 \mathrm{~m}$ \\
$4-5$ & $180 \mathrm{~km}$ Ingress at $0.8 \mathrm{M} / 250 \mathrm{~m}$ \\
$5-6$ & Payload drop \\
$6-7$ & 180 km Egress $0.8 \mathrm{M} / 250 \mathrm{~m}$ \\
$7-8$ & Minimum time to climb $0.8 \mathrm{M} / 12200 \mathrm{~m}$ \\
$8-9$ & Cruise in segment $0.8 \mathrm{M} / 12200 \mathrm{~m}, 1400 \mathrm{~km}$
\end{tabular}


Table 3 Basic performance requirements

\begin{tabular}{|c|c|}
\hline Payload & Internal 2xMk-84 JDAM $\approx 1850 \mathrm{~kg}$ \\
\hline Field performance & Conventional take-off and landing $\leq 1500 \mathrm{~m}$ at sea level \\
\hline Specific Excess Power & $\geq 60 \mathrm{~m} / \mathrm{s}$ at $0.4 \mathrm{M} / 1500 \mathrm{~m}\left(\mathrm{n}_{\mathrm{z}}=1\right.$, full payload $)$ \\
\hline Instantaneous turn rate & $20 \mathrm{deg} / \mathrm{s}$ at $0.7 \mathrm{M} / 4500 \mathrm{~m}$ \\
\hline Static Margin & $\pm 15 \%$ \\
\hline Avionics mass & $225 \mathrm{~kg}$ \\
\hline
\end{tabular}

\section{Baseline UCAV design}

A baseline configuration consisting of a 57 degree leading edge sweep flying wing with a central, no re-heat turbofan engine of moderate by-pass ratio, twin internal weapon bays, tricycle landing gear, and conventional trailing edge control surfaces has been designed. A straight leading edge cranked wing has been assumed due to its good aerodynamic efficiency, and a good compromise between its central length and span for easier systems integration (Whittenbury, 2011). Carrier compatibility has not been considered during this study.

This configuration has a reference area of $52.5 \mathrm{~m}^{2}$, a total wingspan of $12.8 \mathrm{~m}$, an overall length of $10.9 \mathrm{~m}$, a MTOM of $7822.2 \mathrm{~kg}$, an OEM of $4845 \mathrm{~kg}$, and a total fuel consumption of $1127 \mathrm{~kg}$. Engine sizing requirements resulted in a sea level thrust of $49.6 \mathrm{kN}$. The design assumes NACA63 airfoils with varying thicknesses and no incidences throughout the span.

The major systems components have been sized and located through the mass estimation and packaging routines. The size and location of the weapon bays and the landing gear bays are a function of achieving acceptable CG locations and ranges, as well as acceptable maximum landing gear loads; interference checks between these components have also been carried out and included in the optimisation sequence. However, detailed systems and structural layout are out of the scope of this research and are subject to further studies. It is worth noting that for all trade studies, the engine bypass ratio, the fan and compressor pressure ratios, as well as the individual component efficiencies have been kept constant, leaving only the overall engine diameter as the main engine scaling factor. A top view schematic of the packaged design is shown in Figure 9, as well as a percentile mass breakdown.

Figure 9 Baseline design top view and mass breakdown.
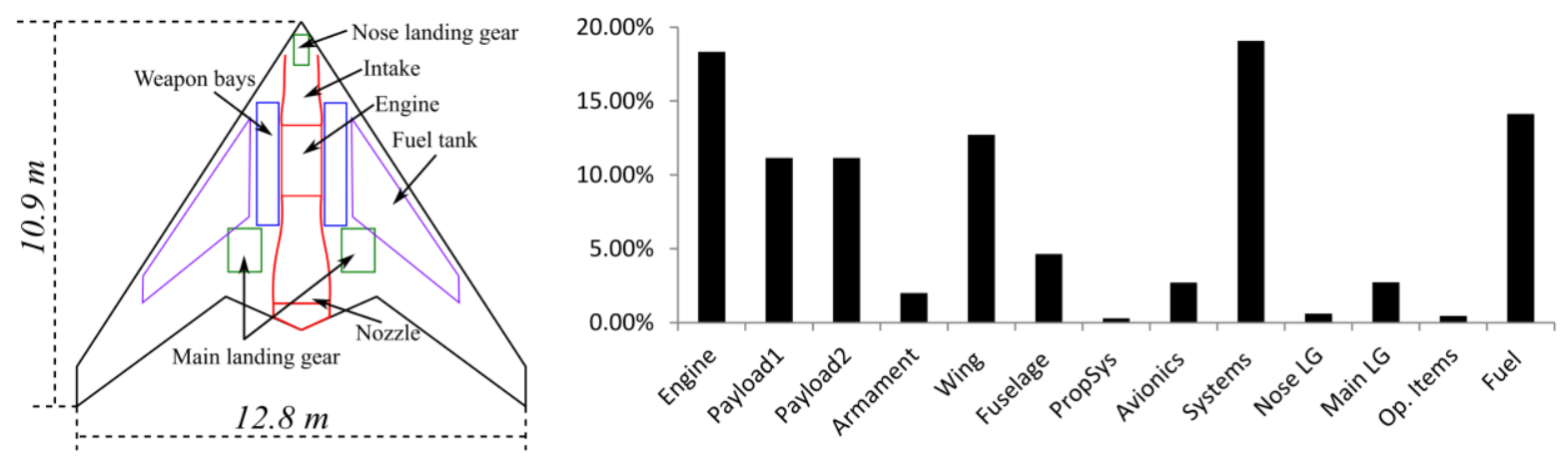
The baseline mission requirements have been evaluated for configurations of varying leading edge sweep angles under constant wing area. Figure 10 a) shows the normalised take-off, empty, and fuel masses with respect to the baseline configuration, as well as the normalised required sea level thrust. It can be seen that the masses and sea level thrust requirement decrease as sweep increases, with a sharp increase in thrust for a leading edge sweep of 30 degrees, which results in a large increase in fuel consumption. The total fuel consumption for a sweep angle of 65 degrees shows a slight increase $(2.1 \%)$ with respect to the baseline configuration due to its significantly lower aspect ratio (1.9 compared to 3.11 ), resulting in an $18 \%$ reduction in aerodynamic efficiency during high altitude cruise segments, which account for around $90 \%$ of the mission range. Drag polars at cruise Mach number and altitude are shown in Figure 11 for all configurations.

The engine throttle settings for high altitude cruise, low altitude ingress and egress, and during the SEP requirement (at $0.4 \mathrm{M} / 1500 \mathrm{~m}$ ) are shown in Figure $10 \mathrm{~b}$ ). It can be seen that for sweep angles higher than 30 degrees, the designs are dominated by manoeuvrability constraints in the form of specific excess power.

Figures $10 \mathrm{c}$ ) and d) show the drag buildup for all configurations during the cruise and ingress/egress segments. During the high altitude cruise segments, a cruise-climb profile flown at the most aerodynamically efficient angle (max L/D) has been assumed, and therefore the lift induced drag accounts for a significant portion of the overall drag; while during the low altitude segments, a constant speed, constant altitude profile has been followed, which results in low induced drag. During the high altitude cruise segments, compressibility drag accounts for nearly $20 \%$ of the total drag, with a sharp decrease observed at sweep angles higher than $50^{\circ}$; at low altitudes and high speeds compressibility drag can account for as much as $60 \%$ of the total drag, diminishing steadily with sweep angle, and being negligible for highly swept configurations.

Figure 10 Normalised mass and thrust (a), throttle setting for cruise, ingress/egress, and SEP requirement (b), drag buildup during cruise (c) and ingress/egress segments (d)

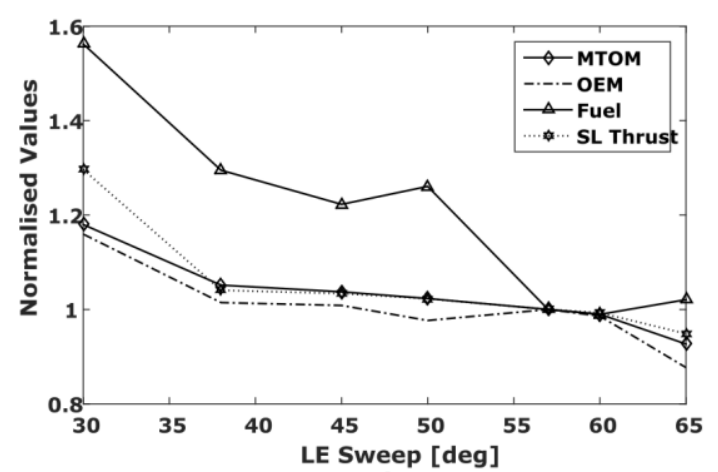

a)

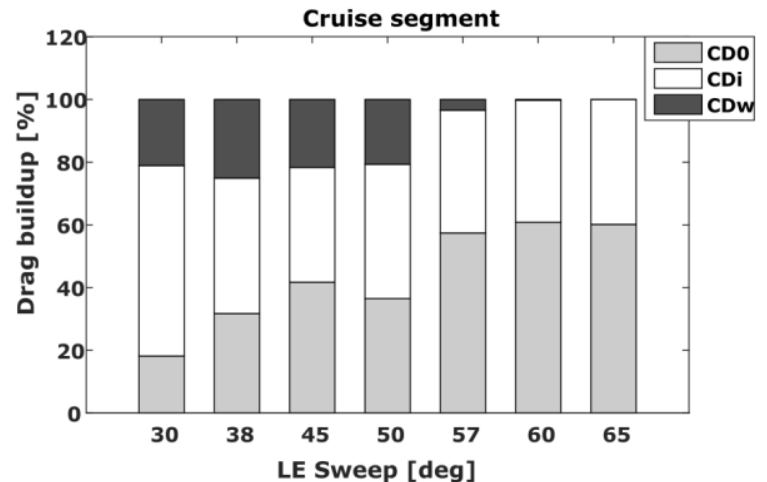

c)

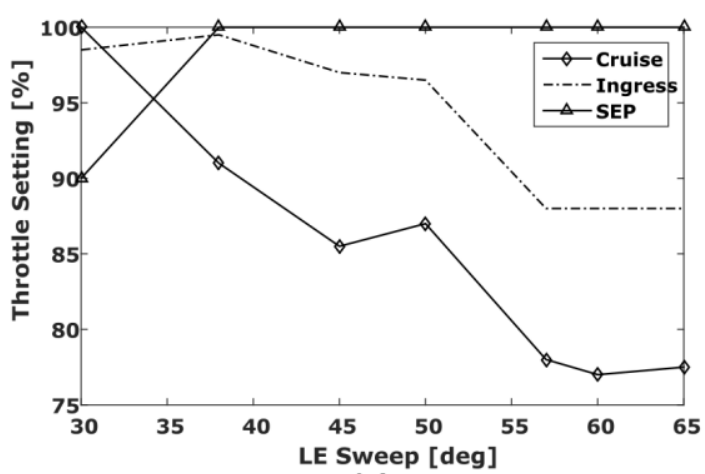

b)

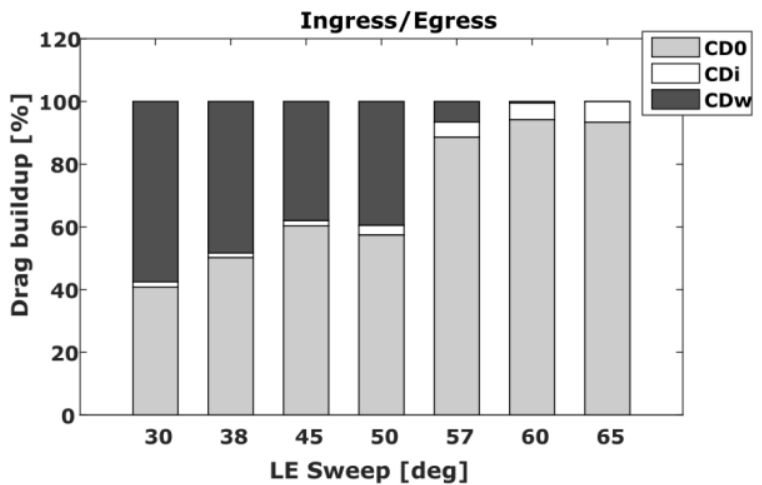

d) 
Figure 11 Drag polar for all configurations at Mach 0.8 and cruise altitude.

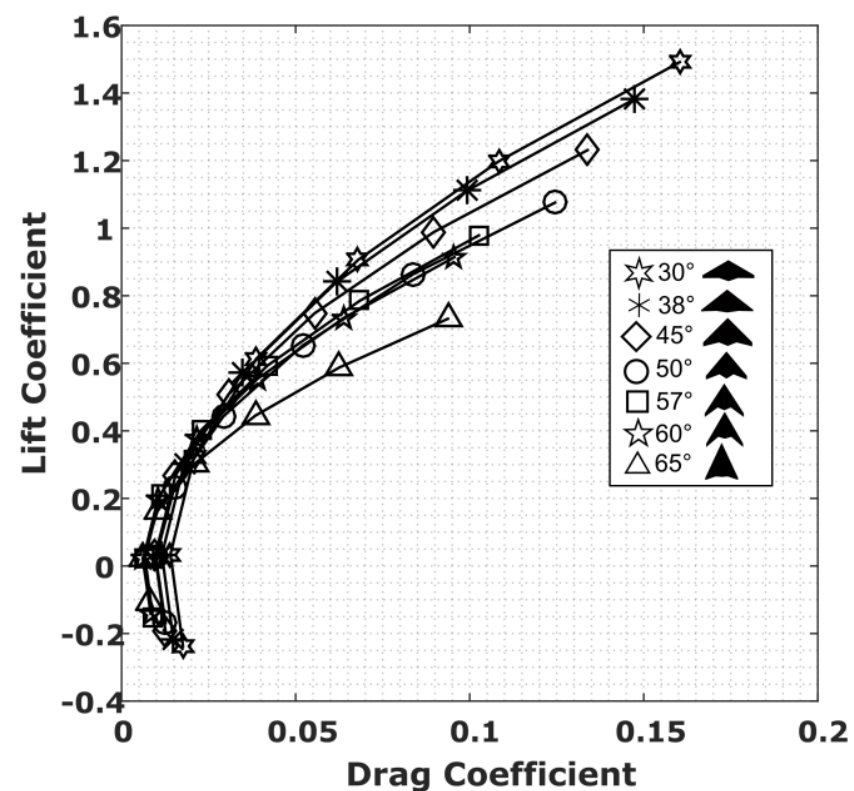

Changes in high-altitude cruise Mach number have been investigated for all configurations for Mach numbers of 0.6 up to 0.9 , while holding the rest of the requirements constant. Take-off, empty, and fuel masses, as well as sea level thrust values are shown in Figure 12 normalised with respect to the baseline configuration. Little to no sensitivity is observed with respect to Mach number for values below 0.8 and all sweep angles. This is mainly related to the performance constraints imposed by the SEP, as shown in Figure 13. At higher Mach numbers, mass and engine size growth clearly show exponential behaviour, and this trend is especially marked for configurations with sweep angles below 50 degrees, for which no realistic solutions were found for Mach 0.9 due to prohibitively large engine sizes and fuel volume constraints. Results also show that the 65 degree sweep configuration remains unaffected by Mach number well into the transonic regime.

Figure 12 Effects of cruise Mach number on MTOM (a), OEM (b), fuel (c), and sea level thrust (d).

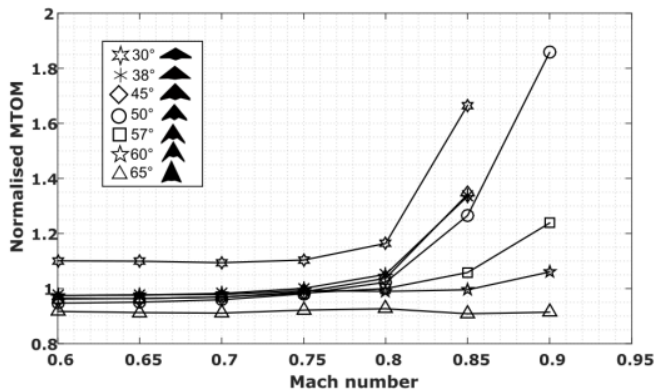

a)

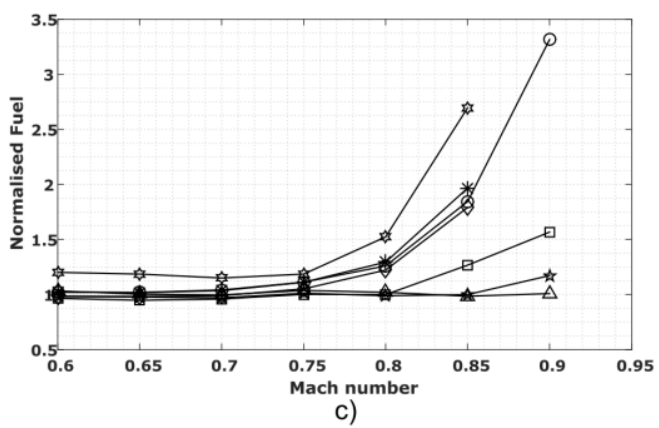

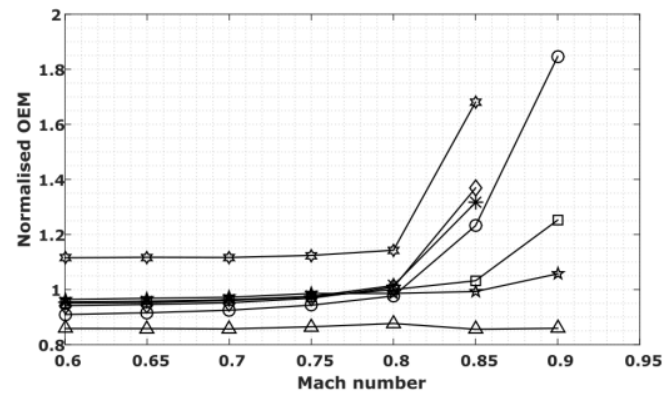

b)

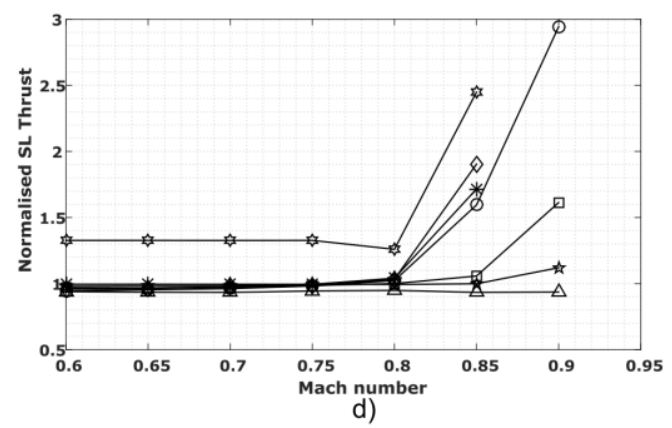


The achieved SEP values at the mission requirement speed and altitude $(0.4 \mathrm{M} / 1500 \mathrm{~m})$ for all cruise Mach numbers and sweep angles are given in Figure 13 by the shaded area and the colorbar values, while the maximum throttle setting (\%) during high altitude cruise or low altitude ingress/egress are given by the labeled contour lines.

From the figure, the areas shaded corresponding to the minimum SEP requirement, and where the throttle values are less than $100 \%$, represent the design space dominated by the SEP requirement. Conversely, the areas showing an achieved SEP value larger than the required minimum (SEP > $60 \mathrm{~m} / \mathrm{s}$ ) and throttle settings approaching $100 \%$ are dominated by increases in thrust demands due to compressibility effects. Table 4 shows the estimated Mach number at which the dominating constraint transitions from the SEP requirement to cruise or ingress thrust requirement.

Table 4 Transition Mach numbers for SEP or thrust constriant.

\begin{tabular}{lc}
\hline Leading Edge Sweep [deg] & Transition Mach number \\
\hline 65 & $\geq 0.9$ \\
60 & 0.88 \\
57 & 0.86 \\
50 & 0.8 \\
45 & 0.8 \\
38 & 0.8 \\
30 & $\leq 0.6$ \\
\hline
\end{tabular}

Figure 13 Specific excess power and maximum throttle setting for various cruise Mach numbers.

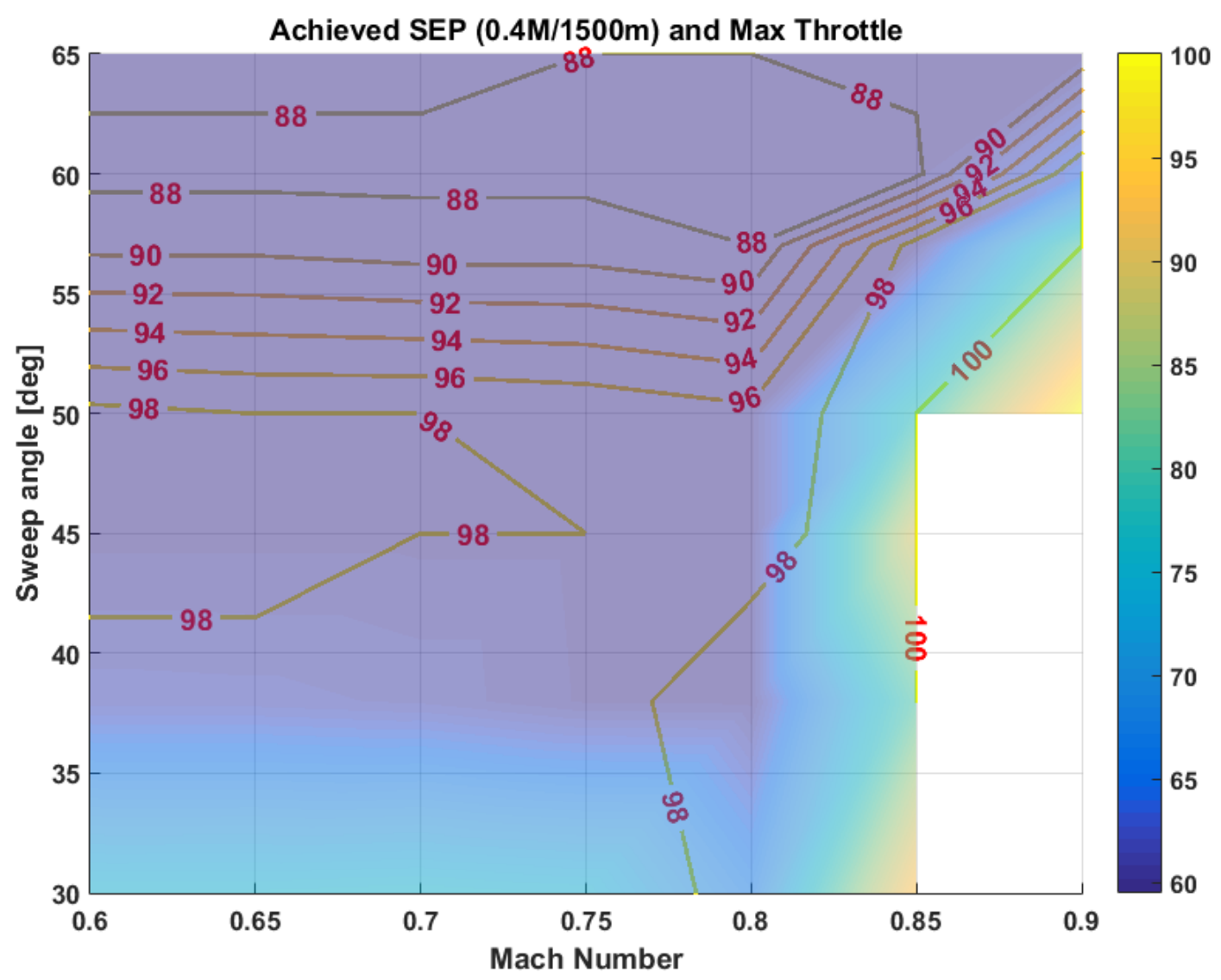


Similarly to the cruise Mach number, the effects of changes in the combat radius requirement have been investigated for all configurations up to a value of twice the baseline range, for a constant cruise Mach number of 0.8. Results in Figure 14 are shown normalised with respect to the baseline configuration.

The effect on MTOM, OEM, and fuel masses, as well as sea level thrust do not show high dependence on sweep angle. The overall mass growth responds to the initial fuel increase due to increased range, which prompts a slight increase in engine size in order to comply with the minimum SEP requirement, which in turn increases OEM and MTOM, until a convergent solution is obtained. This trend is clearly illustrated by the 30 degree sweep configuration, which shows no sea level thrust increase until a normalised combat radius value of 1.5 is reached, after which point the increase in mass requires a larger engine to comply with the SEP requirement.

Figure 14 Effect of increasing combat radius $\left(\mathrm{M}_{\mathrm{Cr}}=0.8\right)$ on MTOM (a), OEM (b), fuel (c), and sea level thrust (d).

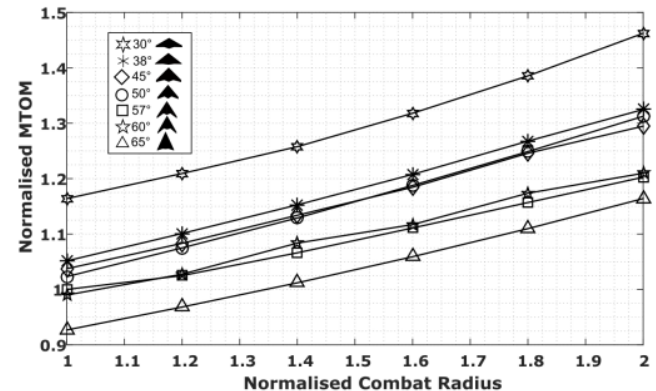

a)

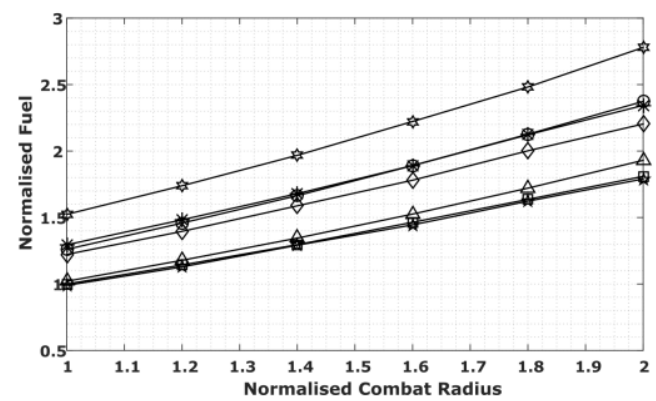

c)

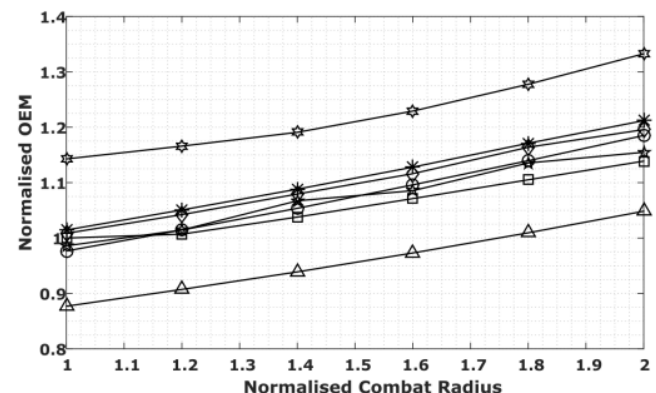

b)

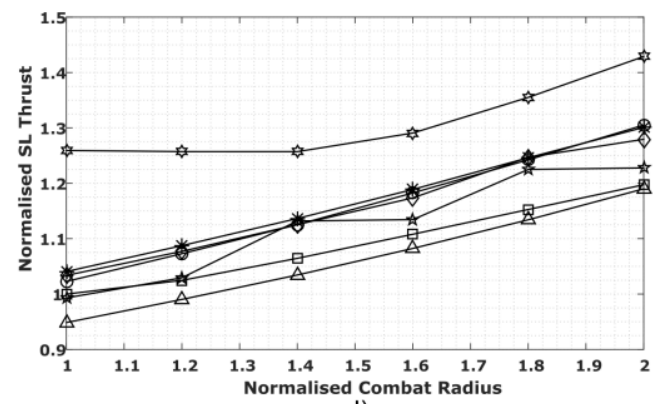

d)

The results obtained thus far highlight the importance of specific excess power and its effect on the overall sizing of the different configurations. Four configurations have been selected for investigating the effect of increasing SEP while maintaining the rest of the mission profile constant. The results shown in Figure 15, which have been normalised with respect to each configuration's baseline results for clarity, show that an increase in SEP from $60 \mathrm{~m} / \mathrm{s}$ to $100 \mathrm{~m} / \mathrm{s}$ results in a sea level thrust increase between $90 \%$ and $100 \%$, resulting in an increase in MTOM of nearly $25 \%$, an OEM increase of approximately $35 \%$, and a fuel increase of $15 \%$. Furthermore, the mass fraction of the engine increases from approximately $16 \%$ up to a value of $25 \%$. 
Figure 15 Effects of specific excess power on MTOM, OEM, fuel, and sea level thrust.
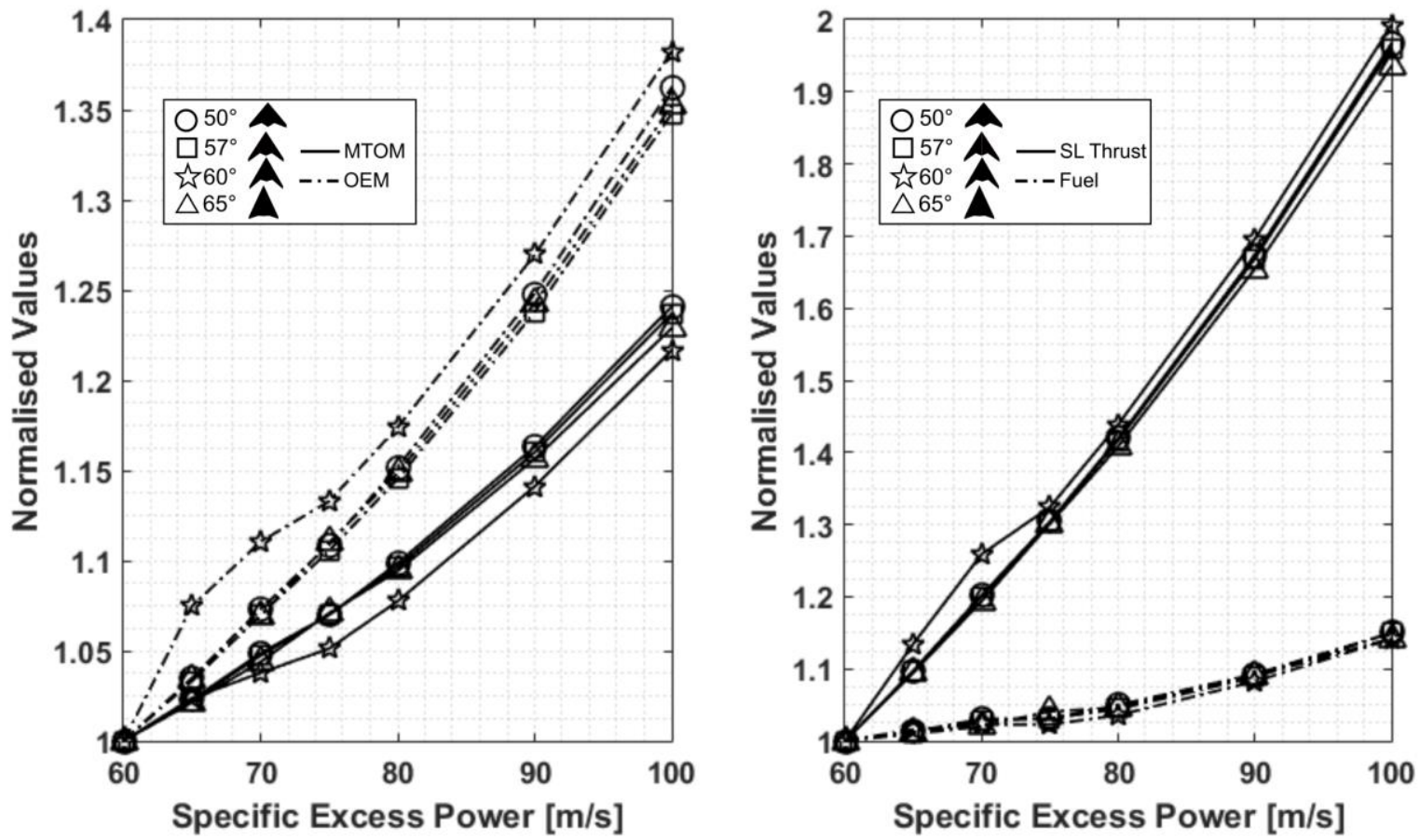

Finally, RCS results for perfect electric conductor materials at a frequency corresponding to the $\mathrm{S}$ band ( $3 \mathrm{GHz}$ ), shown in Figure 16, also benefit the higher sweep configurations, especially for the $\phi=\left[-30^{\circ}, 30^{\circ}\right]$ range. These results can only represent a top-level indication of which configurations might outperform the rest. A more detailed study including careful material choices, internal structural and systems arrangements, as well as a detailed inlet and exhaust geometries is required in order to draw any significant conclusions in terms of stealth.

Figure 16 RCS for perfect electric conductor, $S$ band $(3 \mathrm{GHz}), \theta=90^{\circ} \phi=\left[0^{\circ}, 360^{\circ}\right]$

0

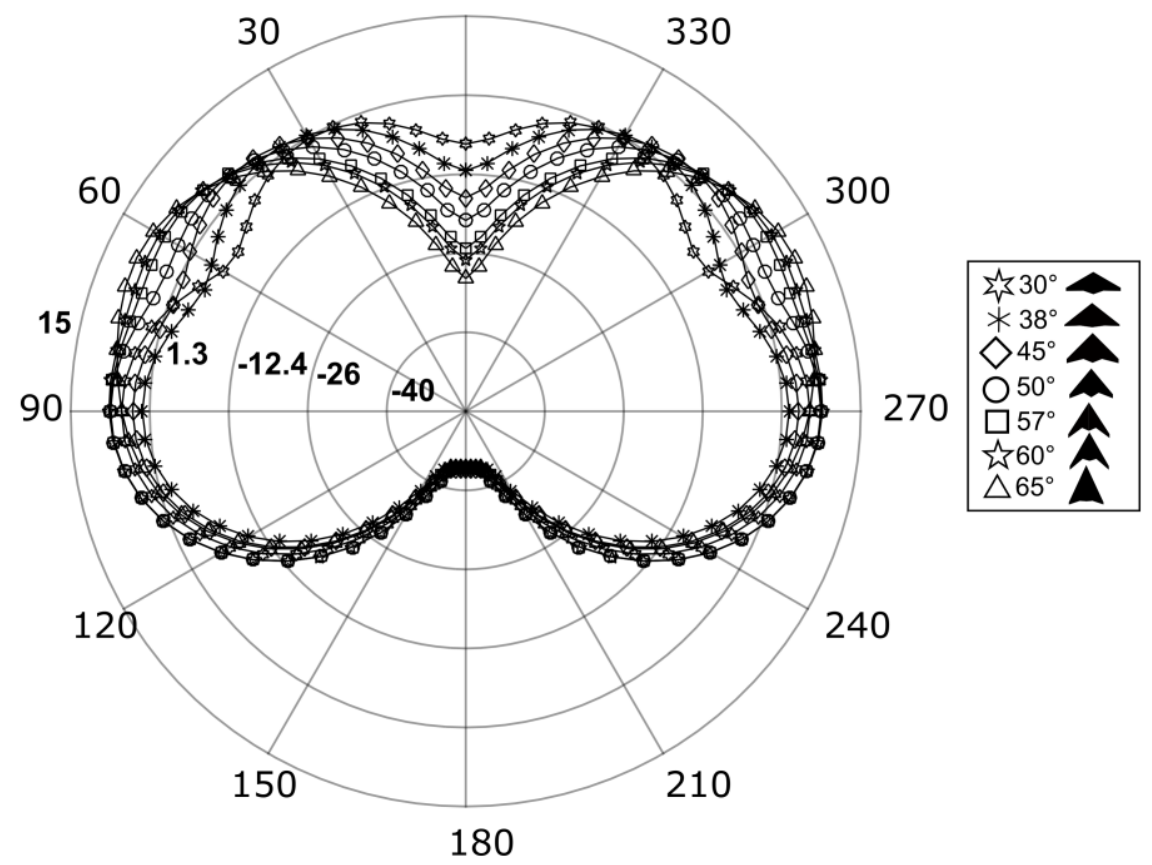


Cost modelling

A basic research, development, testing and evaluation (RDT\&E) cost model based on the RAND DAPCA IV method (Boren Jr, 1967) has been integrated into the GENUS framework. Hourly rates have been estimated and are shown in Table 5. Additionally, to account for the cost of advanced avionics and software development costs of modern combat aircraft, a factor of $20,000 \$ / \mathrm{kg}$ of avionics has been added to the total research and development cost. Furthermore, all calculated man-hours have been increased by $20 \%$ in order to account for the use of composite materials.

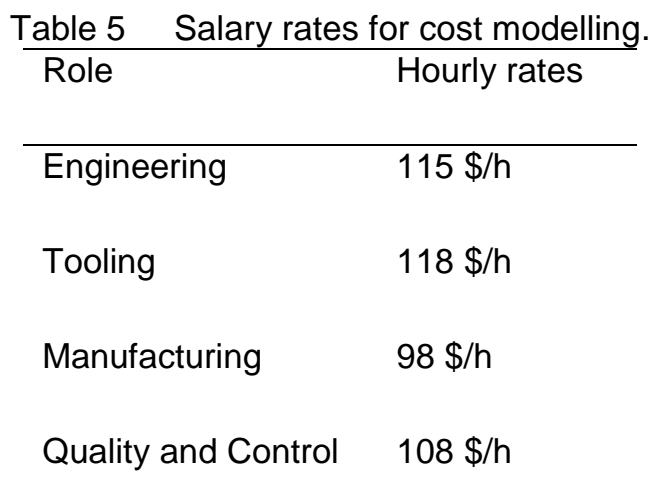

Figure 17 shows the cost per aircraft $(\mathrm{CPA})$ as a function of production number over a five year period, and CPA against normalised combat radius for a fixed production number. It can be seen that CPA decreases exponentially with respect to production number. Furthermore, the similarities between CPA and sea level thrust as a function of normalised combat radius (Figure 14) clearly show a high dependence of cost on the overall engine sizing.

Figure 17 CPA against production number and normalised combat radius
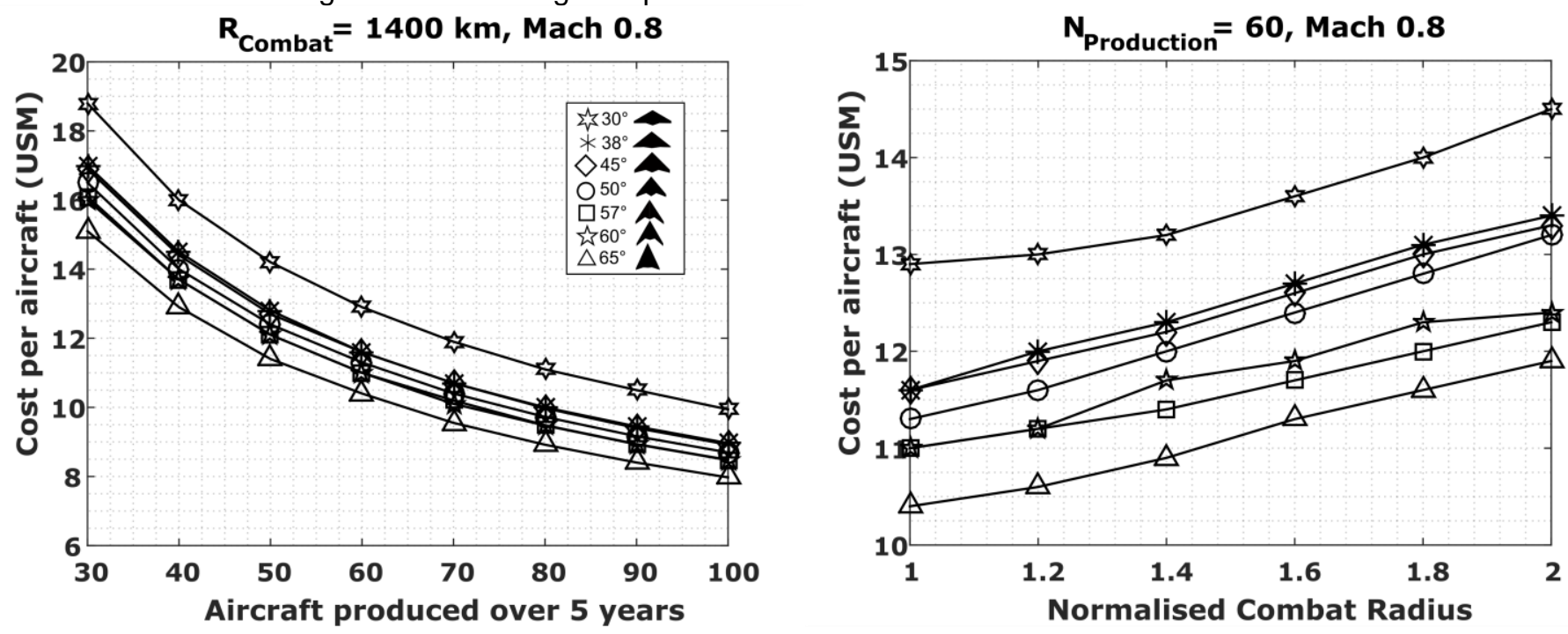

\section{Conclusion}

This paper has introduced the importance of unmanned aerial vehicles in the future concept of aerial warfare, and their possible roles as force multipliers and 'loyal wingmen' in highly dynamic environments strongly influenced by the transformational challenges of fifth generation technologies.

Subsequently, the main conceptual design methodologies appropriate for low observable, subsonic Unmanned Combat Aerial Vehicles, and their integration into Cranfield University's GENUS aircraft design environment have been described. The validation and verification of these design methodologies have also been presented. 
In this study, several mission and operational aspects of a typical ground strike, Hi-Lo-Hi mission have been investigated and their effects on the charactersitics of flying wing configurations of varying leading edge sweep angles have been presented.

Results highlight the effect that including performance requirements consistent with strike and S/DEAD missions has on the overall sizing of tailless configurations, irrespective of sweep angle. This is clearly shown by the fact that reducing the cruise Mach number while holding these performance constraints constant shows no advantages in terms of gross, empty, or fuel masses for all configurations. However, increasing the cruise Mach number to the highly subsonic, and transonic regime $(M>0.8)$ results in drastic mass and engine size increases, except for the highly swept configurations, which delay the effects of compressibility drag.

Changes in the mission range resulted in mass growth trends not heavily influenced by leading edge sweep. The main sizing factor is once more the engine requirements, particularly specific excess power.

Increasing the specific excess power requirement to values more akin to those of air-to-air combat missions shows significant increases in mass and engine thrust requirements, even for those configurations with very high leading edge sweep angles. An increase in SEP from $60 \mathrm{~m} / \mathrm{s}$ to $100 \mathrm{~m} / \mathrm{s}$ resulted in nearly a $100 \%$ increase in sea level thrust, with approximately a $35 \%-40 \%$ increase in OEM, $20-25 \%$ increase in MTOM, and a $15 \%$ increase in total fuel consumption.

Furthermore, top-level RCS calculations favour highly swept configurations, specially from a frontal view aspect within the $\phi=\left[-30^{\circ}, 30^{\circ}\right]$ range. Finally, the basic RDT\&E cost calculations show a significant dependence with engine sizing and operating empty mass.

Further studies will focus on the effects of carrier compatibility on aerodynamics, performance, and structures integration, as well as a more in-depth look at stealth measures, including radar absorbent materials and structures.

These results support the future view of aerial warfare, and the important role that cost-effective unmanned combat aircraft will play in conjunction with advanced fifth generation forces.

\section{References}

Adamson, A. and Snyder, M. (2017), "The challenge of fifth-generation transformation", The Rusi Journal, Vol. 162 No. 4, pp. 60-66.

AIAA. (n.d.). "Draft from the AIAA Unmanned Strike Fighter RFP for AIAA Team Student Design Competition", available at: http://www.dept.aoe.vt.edu/ mason/Mason_f/SD1RFP.pdf.

BAE Systems. (2019), "BAE Systems wins DARPA contract for autonomous air mission planning software", available at: https://www.baesystems.com/en/article/darpa-awards-bae-systems-contract-to-further-develop-autonomoussoftware-for-air-mission-planning (accessed 29 September 2019).

Benson, T.J. (1995), “An Interactive Educational Tool for Turbojet Engines”, NASA Lewis Research Center, Cleveland, Ohio, May, available at: https://www.grc.nasa.gov/www/k-12/airplane/EngineTheory.pdf.

Bevilaqua, P.M. (2009), "Genesis of the F-35 Joint Strike Fighter”, Journal of Aircraft, Vol. 46 No. 6, pp. 1825-1836.

Boren Jr, H.E. (1967), “DAPCA: A computer program for determining aircraft development and production costs”, The RAND Corporation, Santa Monica, California, February.

Chatzigeorgiadis, F. (2004), Development of Code for a Physical Optics Radar Cross Section Prediction and Analysis Application, Naval Postgraduate School.

Cranfield College of Aeronautics. (n.d.). "Subsonic Aircraft Design: Parametric Analysis - Additional Constraints for Military Aircraft". 
Dixon, J.R. (2000), UAV Employment in Kosovo: Lessons for the Operational Commander, Newport.

ESDU. (1991), Energy Height Method for Flight Path Optimisation - ESDU 91016.

Frey Jr, T.L., Aguilar, C.J., Engebreston, K.R., Faulk, D.K. and Lenning. (2018), “F-35 Information Fusion”, 2018 Aviation Technology, Integration, and Operations Conference. 25-29 June. Atlanta, GA, AIAA, Reston, VA, available at:https://doi.org/10.2514/6.2018-3520.

Garrido, E.J. (2000), Graphical User Interface For A Physical Optics Radar Cross Section Prediction Code, Naval Postgraduate School, September.

Gudmundsson, S. (2014), General Aviation Aircraft Design: Applied Methods and Procedures, 1st ed., ButterworthHeinemann, Oxford.

Gundlach, J. (2012), Designing Unmanned Aircraft Systems - A Comprehensive Approach, 1st ed., American Institute of Aeronautics and Astronautics, Reston, VA.

Gur, O., Mason, W.H. and Schetz, J. (2010), "Full-Configuration Drag Estimation”, Journal of Aircraft, Vol. 47 No. 4, pp. 1356-1367.

Haider, A. (2014), Remotely Piloted Aircraft Systems in Contested Environments: A Vulnerability Analysis, Kalkar, Germany.

Howe, D. (2000), Aircraft Conceptual Design Synthesis, Professional Engineering Publishing Limited, London.

Jane's 360. (2019), “Aero India 2019: HAL unveils Unmanned Wingman concept", available at: https://www.janes.com/article/86831/aero-india-2019-hal-unveils-unmanned-wingman-concept (accessed 29 March 2019).

Jenn, D.C. (2005), Radar and Laser Cross Section Engineering, 2nd ed., American Institute of Aeronautics and Astronautics, Reston, VA.

Lewis, S.J. (1994), "The use of carbon fibre composites on military aircraft", Composites Manufacturing, Vol. 5 No. 2, pp. 95-103.

Lloyd, J.E. (2004), “QuickHull3D”, available at: https://www.cs.ubc.ca/ /loyd/java/quickhull3d.html.

Lynn, S. and Pete, M. (1994), "takeoff2.c", Virginia Tech, Blacksburg, VA, available at: http://www.dept.aoe.vt.edu/ mason/Mason_f/MRsoft.html\#TakeOff.

MacDiarmid, I. (2010), "The survivability balance", Encyclopedia of Aerospace Engineering, available at:https://doi.org/10.1002/9780470686652.eae440.

MathWorks. (2012), "POFACETS4.1", available at: http://www.mathworks.com/matlabcentral/fileexchange/35861pofacets4-1 (accessed 17 March 2016).

McParlin, S.C., Bruce, R.J., Hepworth, A.G. and Rae, A.J. (2006), "Low Speed Wind Tunnel Tests on the 1303 UCAV Concept, AIAA 2006-2985", 24th Applied Aerodynamics Conference. San Francisco, California 5-8 June, AIAA, Reston, VA.

NASA Glenn Research Center. (2015), "EngineSim Version 1.8a", EngineSim, available at: https://www.grc.nasa.gov/WWW/k-12/airplane/ngnsim.html (accessed 23 June 2017).

Petterson, K. (2006), "Low-Speed Aerodynamic and Flowfield Characteristics of a UCAV, AIAA 2006-2986", 24th Applied Aerodynamics Conference. San Francisco, California 5-8 June, AIAA, Reston, VA, available at:https://doi.org/10.2514/6.2006-2986.

Rao, G.A. and Mahulikar, S.P. (2002), "Integrated review of stealth technology and its role in airpower", The Aeronautical Journal, Vol. December, pp. 629-641.

Raymer, D.P. (1992), Aircraft Design: A Conceptual Approach, edited by Przemieniecki, J., 2nd ed., AIAA, Washington D.C. 
Resetar, S.A., Rogers, J.C. and Hess, R.W. (n.d.). Advanced Airframe Structural Materials: A Primer and Cost Estimating Methodology. AD-A253 371.

Roskam, J. (1985), “Airplane Design Part V: Component Weight Estimation”, Airplane Design, Roskam Aviation and Engineering Corporation.

Sepulveda, E., Smith, H. and Sziroczák, D. (2018), "Multidisciplinary analysis of subsonic stealth unmanned combat aerial vehicles", CEAS Aeronautical Journal, available at:https://doi.org/10.1007/s13272-018-0325-0.

Sidwell, K.W., Baruah, P.K., Bussoletti, J.E., Medan, R.T., Conner, R.S. and Purdon, D.J. (1990), PAN AIR: A Computer Program for Predicting Subsonic or Supersonic Linear Potential Flows about Arbitrary Configurations Using a Higher Order Panel Method. NASA CR-3252, Volume II - User's Manual (Version 3.0), Seattle, Washington.

Smith, H. (1999), "Uninhabited Tactical Aircraft U-99: Project Specification (Issue 1)", Cranfield University - College of Aeronautics (Unpublished), Cranfield, September.

Smith, H. (2003), "Joint Services Unmanned Combat Air System: U-3 - Project Specification (Issue 1)", Cranfield University (Unpublished), Cranfield, October.

Smith, H., Sziroczák, D., Abbe, G. and Okonkwo, P. (2018), "The GENUS aircraft conceptual design environment”, Proc. IMechE Part G: Journal of Aerospace Engineering, available at:https://doi.org/10.1177/0954410018788922.

Smith, S. and Lasdon, L. (1992), "Solving large sparse nonlinear programs using GRG”, ORSA J. Comput, Vol. 4, pp. 115.

Stillion, J. (2015), "Trends in air-to-air combat: Implications for future air superiority", Center for Strategic and Budgetary Assessments.

Sun, Y. and Smith, H. (2018), "Supersonic Business Jet Conceptual Design in a Multidisciplinary Design Analysis Optimization Environment", AIAA/ASCE/AHS/ASC Structures, Structural Dynamics, and Materials Conference. 8-12 January. Kissimmee, Florida, AIAA, Reston, VA, available at:https://doi.org/10.2514/62018-1651.

Tomac, M., Rizzi, A., Nangia, R.K., Mendenhall, M.R. and Perkins, S.C. (2010), "Engineering Methods on the SACCON Configuration - Some Design Considerations, AIAA 2010-4398", 28th AIAA Applied Aerodynamics Conference. Chicago, Illinois 28 June - 1 July, Reston, VA, available at:https://doi.org/doi:10.2514/6.2010-4398.

UK Defence Journal. (2019), "Boeing introduces new unmanned aircraft", available at: https://ukdefencejournal.org.uk/boeing-introduces-new-unmanned-aircraft/ (accessed 29 March 2019).

Verhaagen, N.G. (2011), "Flow over $50^{\circ}$ Delta Wings with Different Leading-Edge Radii, AIAA 2011-991", 49th AIAA Aerospace Sciences Meeting Including the New Horizons Forum and Aerospace Exposition. Orlando, Florida 4-7 January, AIAA, Reston, VA, available at:https://doi.org/10.2514/6.2011-991.

Virginia Tech. (n.d.). "Program FRICTION”, available at: http://www.dept.aoe.vt.edu/ mason/Mason_f/FRICTman.pdf.

Whittenbury, J. (2011), "Configuration Design Development of the Navy UCAS-D X-47B, AIAA 2011-7041", AIAA Centennial of Naval Aviation Forum "100 Years of Achievement and Progress". Virginia Beach, Virginia 21-22 September, AIAA, Reston, VA, available at:https://doi.org/10.2514/6.2011-7041.

Wikipedia. (n.d.). "Boeing Phantom Ray", available at: https://es.wikipedia.org/wiki/Boeing_Phantom_Ray (accessed 2 May 2016a).

Wikipedia. (n.d.). "Northrop Grumman X-47B", available at: https://es.wikipedia.org/wiki/Northrop_Grumman_X-47B (accessed 2 May 2016b).

Wise, K.A. (2003), "First Flight of the X-45A Unmanned Combat Air Vehicle (UCAV), AIAA 2003-5320", AlAA Atmospheric Flight Mechanics Conference and Exhibit. Austin, Texas 11-14 August, AIAA, Reston, VA, available at:https://doi.org/doi:10.2514/6.2003-5320.

Wright-Patterson AFB. (2019), "XQ-58A Valkyrie demonstrator completes inaugural flight", available at: 
https://www.wpafb.af.mil/News/Article-Display/Article/1777743/xq-58a-valkyrie-demonstrator-completes-inauguralflight/ (accessed 29 March 2019). 
2019-07-09

\section{Impact of mission requirements on the design of low observable UCAV configurations}

Sepulveda Palacios, Eduardo

Emerald

Sepulveda E, Smith H. (2019) Impact of mission requirements on the design of low observable UCAV configurations. Aircraft Engineering and Aerospace Technology, Volume 91, Issue 10, October 2019, pp. 1295-1307

https://doi.org/10.1108/AEAT-09-2018-0249

Downloaded from Cranfield Library Services E-Repository 